\title{
DEVELOPMENT OF PRIMARY SCHOOLS IN THE CONTEXT OF DUAL CAREER
}

\author{
Rihards Parandjuks \\ University of Latvia, Latvia
}

\begin{abstract}
The concept of dual careers is based on the principles of the Olympic Charter with harmony of the mind and body at its core. Contemporary education systems are goal-oriented and neglect their responsibility to aid in the personal development of students. The role of sports is not sufficiently emphasized in the educational process. In order to draw attention to these issues, the author has initiated a dual career development project 'Sports class' with the financial support of Césis Municipality. The project launched on September 1, 2019. The study population was grade $7 a$ of Cēsis Secondary School enrolled in extra physical education classes. To attain the main aim of dual career of combining education and sports, all participants needed to achieve a certain average mark in academic subjects. This research aims to determine the overall results of the project in the first semester of the academic year 2019/2020. Research methods included quantitative methods (surveys) with 83 participants and qualitative methods with 5 interviewees. Data collection and analysis were done using Windows SPSS. The three dependent variables were academic results, progress in sports and personal development. The acquired data show significant progress in all variables. Thus, it is possible to recognize the positive role of sports in overall academic achievement. As a result, the scope of the project will be expanded and continued in the future.
\end{abstract}

Keywords: dual career, education, primary school, sports.

\section{Introduction}

There is increasing awareness of the potential effects and benefits exercise can have on our health. This tendency has been growing over time, however, several factors have greatly contributed to the improved outlook on exercise in modern society.

Primarily it is linked to changes in stereotypes associated with the academic achievements of athletes and their access to high-quality education. This concept is known as a dual career (Lee \& Sum, 2017). In countries such as Germany and France, sports governing bodies have been providing athletes with the opportunity to concurrently train, attend competitions and obtain an education for over a decade. The main aim of this system is to avoid cases when athletes are unable to study due to commitment to the sport, which subsequently has a negative impact on their access to the job market (Knight et al., 2018). 
The author of this research paper wishes to focus on the current situation in Latvia, which is improving, yet a number of issues are hindering further development. Potential solutions to the problems would include allocating additional financial resources and developing infrastructure. Nevertheless, work on developing a dual career system is actively pursued. For example, the Latvian Olympic Committee has instituted a project 'Sport in class' and universities are offering support for their student-athletes.

This research paper is based on the first phase of the project 'Sports class' implemented by the author. It complies with the first stage prescribed by the European Union Guidelines on Dual Careers of Athletes, where sport and education are combined at primary and secondary schools (European Guidelines on Dual Career of Athletes, [EG], 2012). The project is intended to serve as the basis for the author's doctoral thesis on dual careers and their development. Currently, the first semester has concluded, thus evaluation of data and results have been performed to analyze potential issues and implement improvements, as the project is planned to be continued and expanded in the future.

In order to realize the full potential of the project 'Sports class', participants were required to fulfill certain criteria, including attaining a certain level of academic achievement and attending weekly sports activities. The range of activities was broad and encompassed an extra physical education class, physiotherapy class, swimming lessons or cross-country skiing lessons.

\section{Literature Review}

The primary source used by the author for information regarding dual careers is the Guidelines on Dual Careers of Athletes issued by the European Union (EG, 2012). They are based on three key principles. Firstly, primary and secondary education institutions have to be introduced to and informed about the concept of dual careers and have to integrate its principles into their education systems. The main emphasis is on the possibility for students to study and train without any interference at the professional level of specific age groups. Secondly, guidelines on dual careers focus on higher education institutions. The system has to support and facilitate student activity in the fields of both education and sports. The final principle concerns the transition stage of a professional athlete in the job market.

During the process of developing the concept of the project, the author together with local sports governing bodies discussed the main goals, which included promoting exercise, sport and a healthy lifestyle among youth while also focusing on academic achievements. These principles conform to the opinions of researchers on dual careers stressing the importance of developing a healthy relationship with exercise at a young age, thus allowing successful implementation of the dual-career system. 
One of the primary goals on a national level would be to improve the economic and social systems to reach the level of European welfare states. This also applies to the dual-career system. The United Kingdom is one of the leading countries that has successfully created an effective student-athlete support system TASS (The Talented Athlete Scholarship Scheme, 2014). Representatives of this organization indicate that appropriate infrastructure, sports medicine, and service staff are major components required for the development of the dual-career system. In the context of this research paper, this example cannot be applied directly as it concerns professional sports. However, appropriate infrastructure is the uniting aspect that has a major role in the development of a dual career system (Tylor, 2014).

Another researcher in sport and exercise (Geranisova \& Ronkainen, 2015) analyzed the potential of dual career and motivation of athletes in Slovakia. The main conclusions were that there is a need for support from family and friends. Infrastructure was only listed as the third most important factor.

The author of the research analyzed another country of a high level of education. Norway has set up a high quality of dual career development system focusing on the age group 16-19 years. It is based on the Norwegian education system rules on compulsory education at the age of 6 and 16. The result continuing education has become a network of private schools providing young people with different opportunities for development. One of them combining learning with sport-school based lesson schedules, extra counseling, and other important factors. A Norwegian education scientist, in her research about dual career, concluded that this kind of education system could become increasingly in demand (Kristiansen, 2017).

In order to successfully develop a dual career, education institutions need to consider several aspects. One of them - the level of teacher education in the context of dual career. The teacher needs to understand and support students who can combine both processes - sport and education. Researchers (Budevica, 2018) analyzed that teachers should not only support students but also encourage them to take part in the dual-career process.

The development of a dual career depends on several factors. An important shared vision of the public policy is how the sports system is developed and the dual-career role played in it (Domville et al., 2018). However, a major contribution can be made to the municipal authorities responsible for sport - most often local sports schools. Their immediate tasks are to promote the popularity of children's sport, to ensure their participation in competitions, and to promote a healthy lifestyle.

Primary schools can contribute to their development by promoting a dual career process - showing interest and initiative in the progress of young people's 
personalities. As a result, schools may increase the number of students or promote their educational achievement.

\section{Methodology}

Aim of the research: To study and analyze the first semester of the dualcareer development project 'Sports class'.

The author conducted a quantitative survey that was completed by 24 students, 12 teachers and 42 parents. All respondents were part of the first 'Sports class'. The relatively low number of respondents is associated with the specifics of the project and the allocated financial resources. Currently, the financial resources are provided by the Cēsis Municipality, which together with the Cēsis Secondary School and Cēsis Sports School, support the author's project. To ensure that the project is successful and can gradually expand, it was initially decided to involve only one class of students. The plan is to open another sports class in the next academic year, which would double the number of respondents.

20 statements with multiple answers based on the Likert scale were given to the respondents. The data were analyzed using Windows SPSS or Microsoft Excel. All respondents replied to a number of statements, however, certain questions were only given to students. Statistical analysis was also performed on data regarding the academic achievements of students to evaluate the significance and effects of the project in regards to academic education.

\section{Research Results}

The author would like to draw attention to the question about the general attitude towards the project 'Sports class'. The total number of respondents was 78. The majority (n-65) of respondents had a favorable rating of the project, indicating that its continuation would be welcome. This positive response of the involved participants is a vital component for the project to function and expand.

Another important question from the survey concerned the direction of the project. A dual career has two components, namely, sport and education. Initially, the focus of the project was to improve the understanding of students about a healthy lifestyle and increasing their responsibility towards education. The replies of respondents to the statement 'The primary direction of sports class is sport' were drastically different. This can be associated with the different outlooks of the three groups of respondents. Certain tendencies can be observed in groups of students, parents, and teachers. Most students agreed to this statement (n-17). However, the tendency was different among teachers and parents. Most teachers disagreed (n-8) with only a few (n-2) choosing to agree. Similar tendencies were also observed in the group of parents (See, Figure 1). All groups of respondents 
assessed the same process. The differences could be explained with the effects of psychological factors. Students focus on activities they perceive as interesting and motivating to achieve results. In this case, the students' priority was physical education classes, and regular classes were considered secondary. Whereas teachers and parents can objectively evaluate the process as they have a better understanding of the underlying notion of the project.

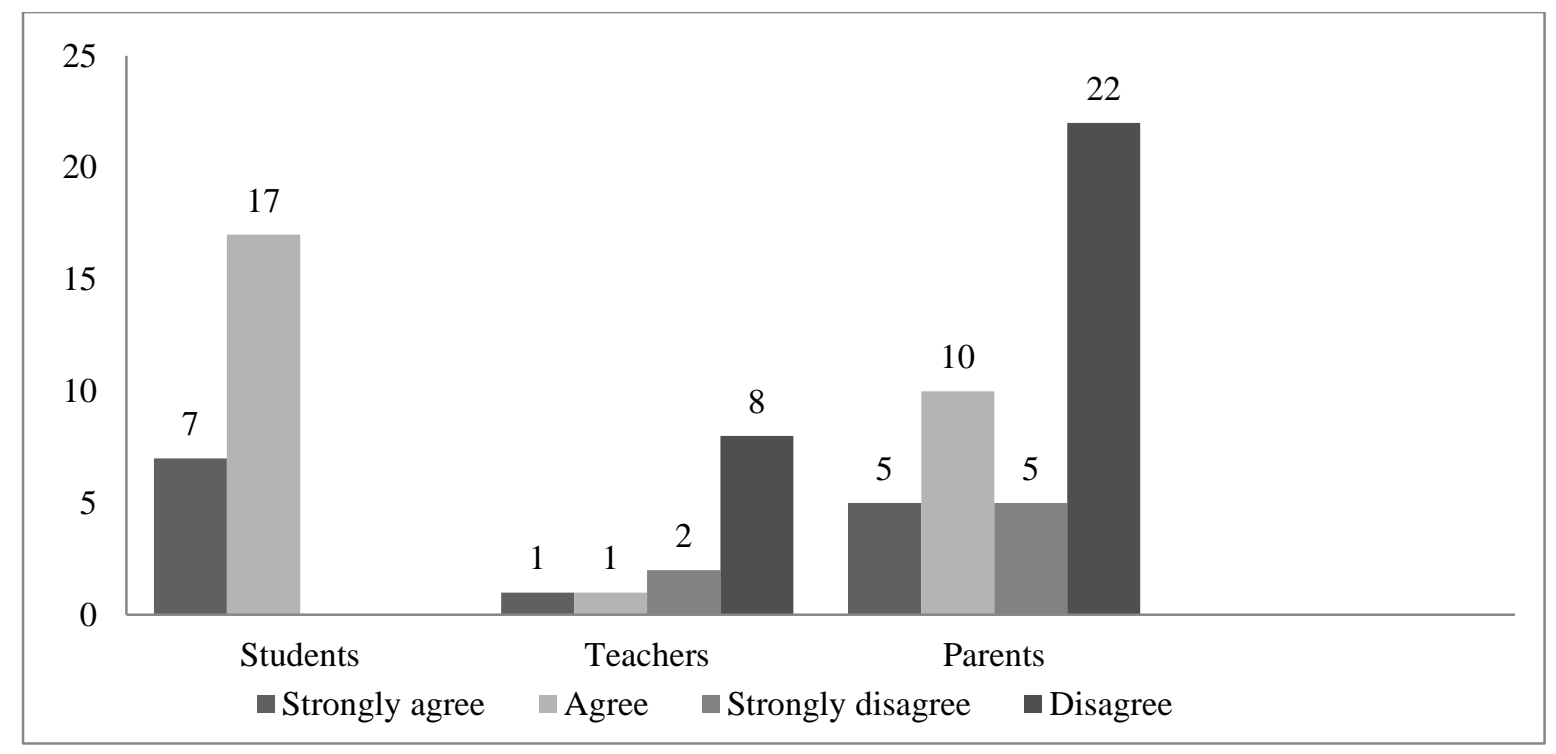

Figure 1 Primary direction of the project

Although according to these replies students mainly focused on sports, the analysis of their academic results showed an opposite trend. In comparison to the previous academic year (when the same students were in grade 6), 16 out of 24 participants of 'Sports class' improved their academic results (average mark). This is an important factor as each subsequent grade becomes more challenging in terms of academic requirements, therefore good marks are more difficult to obtain. When compared to the average mark of the entire school, the results of the 'Sports class' (average mark 6.6) fell just below the school average (6.9). These statistics are important for project development as they indicate the impact of the dual career process. In this case, the results may have been better.

Certain data obtained from the survey were analyzed using Windows SPSS. These were the statements focused on the practical aspects of dual careers and answered only by students. Several correlations were acquired. There was a correlation between statements 8 and 10. It was statistically significant as the pvalue was 0.00 . The statement was that 'Already prior to the project, I focused on combining sport and studies' and 'This project helped me understand the notion of dual career and focus on both studies and sport'. The correlation was 0.405, (See, Table 1) which is not high. Therefore, it cannot be implied that the project 
has radically changed the outlook of students on the primary direction of a dual career. This can be linked to the target group of the project. Most participants involved in the project had already attended Cessis Sports School prior to the project, thus sport was already an integral part of their daily lives.

Table 1 Correlation coefficient of the statements

\begin{tabular}{|c|c|c|c|c|c|c|c|c|c|c|c|}
\hline \multirow[t]{3}{*}{$\begin{array}{l}8 . \\
\text { Assertion }\end{array}$} & \multirow{3}{*}{\begin{tabular}{|l} 
Correla- \\
tion \\
Coeffi- \\
cient \\
Sig.(2- \\
tailed)N
\end{tabular}} & $\begin{array}{r}, 298 * \\
*\end{array}$ & ,225* & ,349* & ,096 & ,154 & ,164 & ,058 &,- 084 & $\begin{array}{r}\text {,405* } \\
*\end{array}$ & 1,000 \\
\hline & & ,006 & ,034 & ,001 & ,370 & ,146 & 126 &, 584 & ,429 & ,000 & \\
\hline & & 73 & 73 & 73 & 73 & 73 & 73 & 73 & 73 & 73 & 73 \\
\hline \multirow[t]{3}{*}{$\begin{array}{l}9 . \\
\text { Assertion }\end{array}$} & \multirow{3}{*}{\begin{tabular}{|l} 
Correla- \\
tion \\
Coeffi- \\
cient \\
Sig.(2- \\
tailed)N
\end{tabular}} & $\begin{array}{r}, 287 * \\
*\end{array}$ &, $290 * *$ &, $327 * *$ &,- 011 &, $331 * *$ & ,229* & ,041 & 141 & 1,000 & ,405** \\
\hline & & ,008 & ,006 & ,002 & 918 & ,002 & ,031 & 693 & 181 & & ,000 \\
\hline & & 73 & 73 & 73 & 73 & 73 & 73 & 73 & 73 & 73 & 73 \\
\hline \multirow[t]{3}{*}{$\begin{array}{l}10 . \\
\text { Assertion }\end{array}$} & \multirow{3}{*}{\begin{tabular}{|l} 
Correla- \\
tion \\
Coeffi- \\
cient \\
Sig.(2- \\
tailed)N
\end{tabular}} &,- 089 & 153 & ,232* & ,096 & 192 & ,218* &, $346 * *$ & 1,000 & ,141 &,- 084 \\
\hline & & ,410 & 148 & ,028 & ,364 & ,069 &, 041 & ,001 & & ,181 & ,429 \\
\hline & & 73 & 73 & 73 & 73 & 73 & 73 & 73 & 73 & 73 & 73 \\
\hline
\end{tabular}

The correlation between the statements selected significant because it is pointing to the current dual career path. Understanding this type of process is important to understand that dual career can change student's attitudes towards learning, which is one of the key standards of dual career.

\section{Conclusions}

This research aimed to study and promote the concept of dual career and its association with the ideology of the Olympic Charter (Olympic Charter, 2004). It was also necessary to investigate and analyze the opinions of the participants involved in the project. Surveys were conducted to obtain this information from students, teachers, and parents participating in the project 'Sports class'. Analysis of the data revealed several important features that should be improved to ensure that further implementation of the project is successful. Primarily this concerns communication with students. Results of surveys show that students do not fully comprehend the notion of the project and do not devote enough attention to their academic subjects. Responsibility for improvement of this issue in the future lies 
with the author, who is also the manager of this project. The other responsibility is that of parents and teachers to attend events that are part of the project. A meeting will be organized to inform participants about the results and future plans.

Thus far the project has proceeded successfully and according to initial plans. The first semester has concluded and a total of 24 students were part of the project. Although the actual length of the project is short, preparation for it has been lengthier. The first meetings and development of the idea began in January 2019. The involved parties included Cēsis municipality, Cēsis Sports School, Cēsis Secondary School, and sports organizations. They decided on initiating a dual career system in Cēsis. It was planned to involve one class of students. The chosen target group was small as it was not known at the time what the number of participants would be from a class of students. In case if the project was simultaneously initiated at different age groups, it was suggested that the number of participants would not reach the desired target.

The author's future perspective of expanding this program is partially based on the results obtained during this research project. For example, in the academic year 2020/2021, it is planned to create another 'Sports class' in the same age group. The class of students currently involved in the project would then be grade 8 students and would continue their study process as previously, namely with a focus on both sport and academic studies. In the next three years, the intention is to have 4 operational 'Sports classes' with around 100 participants.

The chosen age group has not been a random choice as adolescents aged 13 to 14 are at a high risk of developing addictions or lack the motivation to study or participate in sports. This project aims to accentuate the important values in life while facilitating the personal development of students.

Considering the aforementioned factors, the author will focus on the measures necessary in order to acquire the financial resources for further implementation of the project.

After analyzing several results of the research, the author concludes that the project has developed a dual career starting point. Student's responses indicate that the emphasis is more on the field of study. At the moment, the main conclusion - not possible to radically change a student's attitude towards sport and education. If the person is focused on learning a direction, it can be facilitated, but cannot radically change their overall perception.

The average grade for sport "'Sport class"' is lower than the average grade for s school, further emphasis will be placed on the motivation of students to improve achievement. As a result, the project will increasingly fulfill the social function of developing the ethics of student's disciple trough sport. 


\section{References}

Budeviča, L. (2018). The Importance of Adopting National Policy Papers on Dual Career in the Field of Sport. Revista Romaneasca petru Educatie Multidimensionala, 10(1), 45-53.

Domville, S., \& Paula, M., \& Dave, J. (2018). Educator perspectives on factors infulencing children's school-based physical activity. Physical Education and Sport Pedagogy, 24(3), 110-118.

Europien Guidelines on Dual Carrers of Athletes. (2012). Recommended Policy Actions in Supports of Dual Carrers in Hihg-Performance Sport. Retrieved from https://ec.europa.eu/assets/eac/sport/library/documents/dual-career-guidelinesfinal_en.pdf

Geraniosova, K., \& Ronkainen, N. (2015). The experience of dual career through Slovak athletes' eyes. Physical Culture and Sport. Studies and Research, 66(1), 53-64.

Knight, C.J., Harwood, C.G., \& Sellars, P.A. (2018). Supporting adolescent athletes' dual careers: The role of an athlete's social support network. Psychology of Sport and Exercise, 38, 137-147.

Kristiansen, E. (2017). Developing Young Athletes: The role of private schools in Norwegian sport system. International Review of the Sociology of Sport, 52(4), 447-469.

Lee, M., \& Sum, R.K.W. (2017). A meta-synthesis of elites athletes experience in dual career development. Asia Pacific Journal of Sport and Social Science, 6(2), 99-117.

Olympic Charter. (2004). International Olympic committee. Retrieved from http://loa.lv/wpcontent/uploads/2011/06/Olimpiska_harta.pdf

The Talented Athlete Scholarship Scheme. Dual career accreditation. (2014). Retrieved from https://www.tass.gov.uk/

Taylor, G. (2014). Dual Career. More than a sport degree. Retrieved from http://enassport.net/wp-content/uploads/2015/12/Taylor.pdf 